\title{
Searching for abrasive wheels characteristics to improve grinding quality of parts from alloy $1933 T 2$
}

\author{
Soler Yakov Iosifovich \\ Candidate of technical sciences, associate professor \\ Technology and Equipment of Mechanical Manufacture \\ Department \\ Irkutsk national research technical university \\ Irkutsk, Russian Federation \\ Email: solera@istu.irk.ru
}

\begin{abstract}
Selection of optimization results of abrasive wheels characteristics of the surface quality with fuzzy logic involvement are carried out in flat grinding conditions of high-strength aluminum alloy $1933 \mathrm{~T} 2$ parts. The quality of grinded surfaces was evaluated using three groups of parameters: roughness, indicators of flatness deviations, microhardness; each of them is represented by measures of position and dispersion: the median and quartile latitudes. Statistical methods do not have complex analysis capability of a large number of process output parameters. According to the results of fuzzy logic modeling in MATLAB environment, it was found that the best cutting abilities of abrasive wheels as a whole complex of the studied parameters during grinding of parts of high-strength aluminum alloy $1933 \mathrm{~T} 2$ were predicted for high porous wheels of silicon carbide green 08C046I12V01P02 and 39C46I12VP with the «good» rating, and the worst -for sinter-corundum 5SG46K12VXP.
\end{abstract}

Keywords-flat grinding; aluminum alloy; abrasive wheel; nonparametric statistics; fuzzy logic

\section{INTRODUCTION}

Aluminum alloys are promising materials that are currently used in many fields of industry and first of all in aviation industry, automobile manufacturing, etc. Final processing has a great impact on the surface layer quality of the parts and, accordingly, on their performance characteristics. Grinding of aluminum alloys parts is characterized by the following features: high cutting speeds, low forces and grinding temperatures and abrasive tool loading [1;2]. It is advisable to use tools with special characteristics for aluminum alloys grinding.

High-porous wheels (HPW) grinding has shown [3] that they can reduce the roughness of the treated surface within the categorical value and can increase the microhardness by 1.4 times. HPW provide a machine time reduction and reduce the cost of operations.

High quality indicators for modern machines and units in aerospace, automotive, electronics and other fields of mechanical engineering require an increase in their accuracy (precision). The problem being solved is multi-purpose and is provided at various stages of the product life cycle by diagnosis, optimization of adaptive

\author{
Nguyen Chi Kien \\ Postgraduate, Technology and Equipment of Mechanical \\ Manufacture Department \\ Irkutsk national research technical university \\ Irkutsk, Russian Federation \\ Email: chikien89irk@gmail.com
}

control of manufacturing, operation in production conditions and at the stage of debugging and repair. For each of them there are special requirements for quality identification, to improve the efficiency of which fuzzy logic (FL) is involved [4]. It is known that fuzzy logic used to create mathematical models based on linguistic considerations, in which the principal role belongs to language and experience of the expert. In this sense, FL is equivalent to the theory of fuzzy sets, i.e. classes with inaccurate, blurred boundaries.

Fuzzy set theory [5-7] is a generalization and rethinking of the most important areas of classical statistics and Cybernetics.

The aim of this study is to optimize the feature selection of abrasive tools taking into account surface qualities of parts made of high strength and aluminum alloy 1933 T2 during pendulum-flat grinding with FL using. The quality of the workpiece surface is characterized by roughness parameters $-R_{a}, R_{\max }, S_{m}$ (GOST 25142-82), the indicators of flatness deviation $\mathrm{EFE}_{\text {max }}, \mathrm{EFE}_{\mathrm{a}}, \mathrm{EFE}_{\mathrm{q}}$ (GOST 24642-81) named the highest, the average and the square mean respectively, and a microhardness HV (GOST 9450-76). Methods of their measurement and calculation are presented in [8].

\section{METHODS OF EXPERIMENTAL STUDY}

The procedure consists of three consecutive stages: the conditions of the full-scale experiment, the techniques of experimental data interpretation on the basis of statistical methods and FL realization.

\section{A. Method of full-scale experiment}

The following conditions of experiments realization were adopted in the work: surface-grinding machine model 3G71M; the object of study - samples of high strength aluminum alloy $1933 \mathrm{~T} 2\left(\sigma_{\mathrm{B}}=480-490 \mathrm{MPa} ; \sigma_{0,2}\right.$ $=175 \mathrm{MPa})$ with dimensions $\mathrm{L} \times \mathrm{B} \times \mathrm{H}=40 \times 40 \times 45 \mathrm{~mm}$, grinded area of which is $\mathrm{L} \times \mathrm{B}$; the shape and size of the is HPW $01250 \times 20 \times 76 \mathrm{~mm}$ [9]; technological parameters speed range $\mathrm{v}_{\mathrm{w}}=35 \mathrm{~m} / \mathrm{s}$, longitudinal feed $\mathrm{s}_{\mathrm{l}}=7 \mathrm{~m} / \mathrm{min}$, cross feed $\mathrm{s}_{\mathrm{c}}=1 \mathrm{~mm} /$ double pass, cutting depth $\mathrm{t}=0.015$ $\mathrm{mm}$, operating allowance $\mathrm{z}=0.15 \mathrm{~mm}$; flooded coolant 5\% emulsion Equal-6 (under 0258-024-00148845-98 specification) with the $7-10 \mathrm{l} / \mathrm{min}$ flow. Spindle with the 
wheel is lowered to a depth $t$ in the time point when the longitudinal table with the workpiece is shifted to the left most position relative to the operator. Taking into account that the scheme $s_{s}$ of specifying the feed is selected in $\mathrm{mm} /$ double-stoke, and abrasive tool has a clockwise rotation; the from-left-to-right table stroke is a working one and runs while the wheel is cutting-in. Its reverse is considered as sparking-out, finally forming the topography of the grinding surface in the conditions of down cutting. The samples were fixed with clamps on the clamping plate of the universal modular fixture that excluded the error of location when the form deviation takes place.

With the aim of an information content reduction, the variable grinding conditions were described by a code (e, i), which is particularly convenient when the response is presented in the form of $y_{\mathrm{ei}}$. The index $\mathrm{e}=\overline{1 ; 7}$ is distributed according to the quality parameters of the surface. Roughness is characterized by the parameters: $R_{a i}=y_{1 i}, R_{\operatorname{maxi}}=y_{2 i}, S_{m i}=y_{3 i}$, which are located on the surface in the vector $\mathrm{s}_{\mathrm{s}}$ direction and exceeding their analogues in the orthogonal direction (along the vector $\mathrm{s}_{\mathrm{l}}$ ). Flatness deviations are estimated by three indicators: main indicator $\mathrm{EFE}_{\text {maxi }}=\mathrm{y}_{4 \mathrm{i}}$ and two auxiliary indicators - arithmetic mean $\mathrm{EFE}_{\mathrm{ai}}=\mathrm{y}_{5 \mathrm{i}}$ and square mean $\mathrm{EFE}_{\mathrm{qi}}=\mathrm{y}_{6 \mathrm{i}}$. Microhardness $\mathrm{HV}_{\mathrm{i}}$ is marked as $\mathrm{y}_{7 \mathrm{i}}$. Code $\mathrm{i}=\overline{1 ; 5}$ characterizes the HPW grains material of black silicon carbide - 37C46I12VP (i=1); green silicon carbide - 39C46I12VP (i=2), 63C40L7V (i=4), 08C046I12V01P02 $(\mathrm{i}=5)$ and synthercorundum 5SG46K12VXP (i=3). Among them only the wheel of Russian production $\mathrm{i}=4$ has normal porosity.

\section{B. Experimental statistics}

The peculiarity of the grinding process is that abrasive grains in the tool have an arbitrary shape, a chaotic arrangement in the bundle, different projection height from the bundle in the radial and axis direction, a different number of active grains and cutting edges per unit of the wheel contact area when cutting-in. The foregoing allows considering the observations as continuous random quantities (RQ) and evaluating their behavior on the basis of probability-theoretic approaches. To accelerate the calculations, we selected the program Statistica 6.1.478.0. The experimental data are presented in the form of independent sets [10-12]:

$$
\left\{\mathrm{y}_{\text {eiv }}\right\}, \mathrm{e}=\overline{1 ; 7}, \mathrm{i}=\overline{1 ; 5}, \mathrm{v}=\overline{1 ; 30}
$$

where $\mathrm{v}$ is the number of parallel experiments, which it is advisable to carry out with the same $\mathrm{v}$ (in this case $\mathrm{v}=$ 30).

In statistics, the following frequencies are used to estimate RQ [13-16]:

- measures of position (reference values) average $\overline{\mathrm{y}}_{\mathrm{ei}}=\mathrm{y}_{\mathrm{ei}}$, medians $\tilde{\mathrm{y}}_{\mathrm{ei}}$;

- measures of dispersion (precision) standard deviations $\mathrm{SD}_{\mathrm{ei}}$, ranges $R_{e i}=\left|y_{\max }-y_{\min }\right|_{e i}$, quartile latitude $\mathrm{QL}_{\mathrm{ei}}=\left|\mathrm{y}_{0,75}-\mathrm{y}_{0,25}\right|_{\mathrm{ei}}$

The parametric method is based on (2), (4), (5), and rank statistics - on (3), (6). Acceptance of the null hypothesis $\mathrm{H}_{0}$ regarding the homogeneity of dispersions and normality of distributions (1) is considered in the paper [8].

\section{The modelling technique of fuzzy logic.}

FL is equivalent to the theory of fuzzy sets $A_{e i}$, i.e. classes with defuse boundaries, which are represented by sets of ordered pairs, composed of elements $y_{\text {eiv }}$ of universal sets $\left\{\mathrm{y}_{\text {eiv }}\right\}$ and the corresponding grades of membership $\mu_{\mathrm{A}}\left(\mathrm{y}_{\text {eiv }}\right)$ :

$$
\mathrm{A}_{\mathrm{ei}}=\left\{\left(\mathrm{y}_{\mathrm{eiv}}, \mu_{\mathrm{A}}\left(\mathrm{y}_{\mathrm{eiv}}\right)\right) \mid \mathrm{y}_{\mathrm{eiv}} \in\left\{\mathrm{y}_{\mathrm{eiv}}\right\}\right\},
$$

where $\mu_{\mathrm{A}}\left(\mathrm{y}_{\text {eiv }}\right)$ are characteristic functions, which indicates the degree of membership $\mathrm{y}_{\text {eiv }}$ of fuzzy sets $\mathrm{A}_{\mathrm{ei}}$.

FL modelling for the experimental values was carried out in MATLAB, using a special bump pack Fuzzy Logic Toolbox. The last one has a simple and welldesigned interface that makes it easy to design and diagnose fuzzy models [5,6]. Desirability function $\mathrm{d}_{\mathrm{ei}}$ proposed by Harrington [13] is used to evaluate the surface quality of workpieces. The idea of conversion the natural values of particular responses into the dimensionless scale of desirability or preference is the basis of the function forming. Scale of desirability refers to the psychophysical categories. FL is implemented as three sequentially executed procedures: differential selection of HPW $\mathrm{i}=\overline{0 ; 5}$ for each parameter of surface quality $\mathrm{e}=\overline{1 ; 7}$; the separate assessments of cutting ability of HPW for all the attributes of roughness $(\mathrm{e}=\overline{1 ; 3})$ and form accuracy $(\mathrm{e}=\overline{4 ; 6})$; integral evaluation of HPW cutting ability for all attributes of output parameters. In terms of non-parametric statistics, the attributes take into account (3) and (6) simultaneously.

\section{STUDY RESULTS AND THEIR DISCUSSION}

Table 1 presents the test results of observations (1) for homogeneity of dispersions (acceptance of $\mathrm{H}_{0}$ ) according to three criteria: 1- Levene's, 2 - Hartley's, Cochran's and Bartlett's (which are presented in the program with one set); 3 - Brown-Forsythe's. In table 1 the sign "+" means that the $\mathrm{H}_{0}$ for (1) was taken at least for two criteria. It was revealed that for all parameters of the surface topography $\mathrm{H}_{0}$ is accepted at a 5\% significance level, i.e. the difference between the variances of deviations for wheels $i=\overline{1 ; 5}$ is random.

TABLE I. TEST (1) OF DISPERSIONS HOMOGENEITY AT A CONFIDENCE LEVEL OF P $=0.05$

\begin{tabular}{|l|c|c|c|c|}
\hline \multirow{2}{*}{ Parameter } & \multicolumn{2}{|c|}{ Expected confidence level p for criteria } & \multirow{2}{*}{$\begin{array}{c}\text { Acceptan } \\
\text { ce of } \mathbf{H}_{\mathbf{0}}\end{array}$} \\
\cline { 2 - 4 } & Levene's & $\begin{array}{c}\text { Hartley's,Coc } \\
\text { hran's and } \\
\text { Bartlett's }\end{array}$ & $\begin{array}{c}\text { Brown- } \\
\text { Forsythe's }\end{array}$ & \\
\hline $\mathrm{R}_{\mathrm{a}}$ & 0.001 & 0.001 & 0.002 & + \\
\hline $\mathrm{R}_{\max }$ & 0.001 & 0.001 & 0.001 & + \\
\hline $\mathrm{S}_{\mathrm{m}}$ & 0.002 & 0.001 & 0.003 & + \\
\hline $\mathrm{EFE}_{\max }$ & 0.001 & 0.003 & 0.001 & + \\
\hline $\mathrm{EFE}_{\mathrm{a}}$ & 0.001 & 0.001 & 0.001 & + \\
\hline $\mathrm{EFE}$ & 0.001 & 0.001 & 0.001 & + \\
\hline $\mathrm{HV}$ & 0.003 & 0.001 & 0.004 & + \\
\hline
\end{tabular}

Verification of observations' distribution normality $\left(\mathrm{H}_{0}\right)$ (1) using the Shapiro-Wilk's test was carried out for all surface parameters separately. Test results for each abrasive wheels are shown in table 2. According to theoretical statistics, $\mathrm{H}_{0}$ occurs when satisfying inequalities: $\mathrm{p}_{\mathrm{i}}>0.5, \mathrm{i}=\overline{1 ; 5}$. Thus, the total number of 
analyzed situations is $\mathrm{N}=7 \times 5=35$. Test results (table 2) showed that $\mathrm{H}_{0}$ have been accepted in 5 of 35 cases, which is highlighted in the table.

Based on two test results, the nonparametric statistics method characterized by the measures (3) and (6) was chosen as «the home field» for interpretation (1). After their statistical interpretation, the measures $\tilde{y}_{\text {ei }}$ and $\mathrm{QL}_{\mathrm{ei}}$, are considered to be input data (table 3) during FL modelling

TABLE II. VERIFICATION OF DISTRIBUTIONS NORMALCY (1) FOR THE SHAPIRO-WILK'S TEST

\begin{tabular}{|c|c|c|c|c|c|}
\hline \multirow{3}{*}{ Parameter } & \multicolumn{5}{|c|}{ Wheel $(\mathrm{i}=\overline{\mathbf{0} ; \mathbf{8}})$} \\
\hline & $\begin{array}{c}37 \mathrm{C} \\
(\mathrm{i}=1)\end{array}$ & $\begin{array}{c}39 \mathrm{C} \\
(\mathrm{i}=2)\end{array}$ & $\begin{array}{c}5 \mathrm{SG} \\
(\mathrm{i}=3)\end{array}$ & $\begin{array}{c}63 \mathrm{C} \\
(\mathrm{i}=4)\end{array}$ & $\begin{array}{c}08 \mathrm{C} \\
(\mathrm{i}=5)\end{array}$ \\
\hline & \multicolumn{5}{|c|}{$\mathrm{H}_{0}$ for normal distribution } \\
\hline $\mathrm{R}_{\mathrm{a}}$ & 0.18 & 0.03 & $\underline{0.82}$ & 0.13 & 0.12 \\
\hline $\mathrm{R}_{\max }$ & 0.16 & 0.01 & 0.38 & $\underline{0.72}$ & $\underline{0.79}$ \\
\hline $\mathrm{S}_{\mathrm{m}}$ & 0.42 & 0.02 & 0.13 & 0.17 & 0.68 \\
\hline $\mathrm{EFE}_{\max }$ & 0.01 & 0.01 & $\underline{\mathbf{0 . 5 3}}$ & 0.11 & 0.13 \\
\hline $\mathrm{EFE}_{\mathrm{a}}$ & 0.03 & 0.01 & 0.13 & 0.03 & 0.25 \\
\hline $\mathrm{EFE}_{\mathrm{q}}$ & 0.02 & 0.01 & 0.02 & 0.05 & 0.12 \\
\hline $\mathrm{HV}$ & 0.12 & 0.12 & 0.25 & 0.01 & 0.18 \\
\hline
\end{tabular}

TABLE III. INPUT DATA OF PARTS SURFACE QUALITY FOR FL MODELING

\begin{tabular}{|c|c|c|c|c|c|c|}
\hline \multirow{2}{*}{$\begin{array}{c}\begin{array}{c}\text { Parame } \\
\text { ter }\end{array} \\
(\mathbf{e}= \\
\overline{1 ; 7})\end{array}$} & \multirow{2}{*}{$\begin{array}{c}\text { Measu } \\
\text { res }\end{array}$} & \multicolumn{5}{|c|}{ Wheel $(\mathrm{i}=\overline{\mathbf{0 ; 8}})$} \\
\hline & & $\begin{array}{c}37 \mathrm{C}(\mathrm{i} \\
=1)\end{array}$ & $\begin{array}{c}39 \mathrm{C}(\mathrm{i} \\
=2)\end{array}$ & $\begin{array}{c}\begin{array}{c}5 S G(\mathrm{i} \\
=3)\end{array}\end{array}$ & $\begin{array}{c}63 \mathrm{C}(\mathrm{i} \\
=4)\end{array}$ & $\begin{array}{c}08 \mathrm{C}(\mathrm{i} \\
=5)\end{array}$ \\
\hline \multirow{2}{*}{$\mathrm{R}_{\mathrm{ai}}(1)$} & $\tilde{y}_{1 \mathrm{i}}$ & 0.327 & 0.3 & 0.327 & 0.364 & 0.189 \\
\hline & $\mathrm{QL}_{1 \mathrm{i}}$ & 0.116 & 0.176 & 0.057 & 0.073 & 0.023 \\
\hline \multirow{2}{*}{$\begin{array}{l}R_{\operatorname{maxi}} \\
\text { (2) }\end{array}$} & $\tilde{y}_{2 \mathrm{i}}$ & 1.951 & 1.828 & 1.925 & 2.278 & 1.101 \\
\hline & $\mathrm{QL}_{2 \mathrm{i}}$ & 0.319 & 0.996 & 0.396 & 0.545 & 0.265 \\
\hline \multirow{2}{*}{$\mathrm{S}_{\mathrm{mi}}(3)$} & $\tilde{y}_{3 \mathrm{i}}$ & 94.7 & 103.9 & 81 & 99.2 & 98.2 \\
\hline & $\mathrm{QL}_{3 \mathrm{i}}$ & 42.2 & 40.9 & 21.2 & 20.3 & 28.4 \\
\hline \multirow{2}{*}{$\begin{array}{l}\mathrm{EFE}_{\text {maxi }} \\
(4)\end{array}$} & $\tilde{\mathrm{y}}_{4 \mathrm{i}}$ & 10 & 6.5 & 20 & 8.5 & 10 \\
\hline & $\mathrm{QL}_{4 \mathrm{i}}$ & 6 & 1.75 & 5 & 4 & 3.25 \\
\hline \multirow{2}{*}{$\begin{array}{l}\mathrm{EFE}_{\mathrm{ai}} \\
(5)\end{array}$} & $\tilde{y}_{5 i}$ & 5.9 & 3.8 & 11.6 & 4.6 & 6.1 \\
\hline & $\mathrm{QL}_{5 \mathrm{i}}$ & 3.4 & 1.0 & 2.3 & 2.7 & 1.9 \\
\hline \multirow{2}{*}{$\begin{array}{l}\mathrm{EFE}_{\mathrm{qi}} \\
\text { (6) }\end{array}$} & $\tilde{y}_{6 \mathrm{i}}$ & 6.3 & 4.2 & 12.6 & 5.3 & 7.5 \\
\hline & $\mathrm{QL}_{6 \mathrm{i}}$ & 3.2 & 1.3 & 2.6 & 2.7 & 1.9 \\
\hline \multirow{2}{*}{$\mathrm{HV}_{\mathrm{i}}(7)$} & $\tilde{y}_{7 \mathrm{i}}$ & 1806 & 1838 & 1612 & 1763 & 1614 \\
\hline & $\mathrm{QL}_{7 \mathrm{i}}$ & 149.8 & 138.5 & 160.1 & 163.6 & 139.3 \\
\hline
\end{tabular}

As can be seen from table 3, the smallest measure of position for the value $R_{a}$ occurs when $i=5$, and for $\mathrm{EFE}_{\text {max }}$ - when $\mathrm{i}=2$. It was found that the greatest process stability for QL has been observed when: $i=5$ for the parameters $\mathrm{R}_{\mathrm{a}}, \mathrm{R}_{\max }$ and $\mathrm{EFE}_{\max }$; and when $\mathrm{i}=2$ - for HV.

It has been established that statistical methods do not give a comprehensive assessment of the parts surface quality, when micro- and macrogeometry is evaluated by three quality parameters; each of them is represented additionally by precision. This also applies to microhardness. In general case, statistical methods can predict the leading position of the HPW on the reference value (2), (3) or forming precision (4)-(6) of one specific parameter of the parts topography. Therefore, FL was involved in our study. In MATLAB modelling the experimental data after their statistical interpretation is usually considered to be input variables: $\tilde{y}_{\mathrm{ei}}, \mathrm{QL}_{\mathrm{ei}}$, $\mathrm{e}=\overline{1 ; 7}, \mathrm{i}=\overline{1 ; 5}$ (table 3 ).

The procedure of FL fulfilment was conducted in three sequentially executed 3 stages:
1. Differential evaluation of HPW cutting ability based on the surface qualities $(i=\overline{1 ; 5})$ for each parameter $(\mathrm{e}=\overline{1 ; 7})$.

2. Differential evaluation of HPW cutting ability on the surface topography for groups of roughness parameters $(e=\overline{1 ; 3})$ and flatness deviations $(e=\overline{4 ; 6})$. In this case, the microhardness indicator $(e=7)$ was excluded because in the surface quality analysis it describes a single feature.

3. Integral choice of the optimal HPW characteristic $\mathrm{i}=\overline{0 ; 8}$ for all quality indicators of the workpiece surface, which made it possible to develop more complete guidelines for flat grinding of high strength aluminum alloy 1933 T2 workpieces.

The results of fuzzy modeling at stages 1 and 2 should be used when solving local problems; for example, for HPW search - considering only the surface roughness or workpiece form accuracy and etc.

The FL procedures are described in the work [14]. Table 4 presents after-first-stage results; they estimated the wheels by the attributes for each parameter separately. First stage results of modelling may be of local interest. In particular, if according to the service requirements for the manufacture of parts only one specific indicator of surface quality should be maintained, it is necessary to ensure only roughness requirement, etc. Table 4 shows that HPW $\mathrm{i}=5-\mathrm{d}_{51}=$ 0.821 has the best cutting ability for $\mathrm{R}_{\mathrm{a}}$ parameter and the worst one HPW $\mathrm{i}=2$ when $\mathrm{d}_{21}=0.191$.

TABLE IV. RESULTS OF THE FUZZY LOGIC DIFFERENTIAL EVALUATION OF HPW I $=\overline{1 ; 5}$ CUTTING ABILITIES

\begin{tabular}{|c|c|c|c|c|c|c|c|}
\hline \multirow{2}{*}{$\begin{array}{c}\text { Wheels } \\
\mathbf{i}=\mathbf{1 ;} \mathbf{5}\end{array}$} & \multicolumn{6}{|c|}{ Desirability functions $\mathbf{d}_{\text {ei }}$ for parameters e $=\overline{\mathbf{1 ; 7}}$} \\
\cline { 2 - 8 } & $\begin{array}{c}\mathrm{R}_{\mathrm{ai}}, \\
\mathrm{y}_{1 \mathrm{i}}\end{array}$ & $\begin{array}{c}\mathrm{R}_{\text {maxi }} \\
, \mathrm{y}_{2 \mathrm{i}}\end{array}$ & $\begin{array}{c}\mathrm{S}_{\mathrm{mi}}, \\
\mathrm{y}_{3 \mathrm{i}},\end{array}$ & $\begin{array}{c}\mathrm{EFE}_{\text {maxi }} \\
\mathrm{y}_{4 \mathrm{i}}\end{array}$ & $\begin{array}{c}\mathrm{EFE}_{\mathrm{ai}} \\
, \mathrm{y}_{5 \mathrm{i}}\end{array}$ & $\begin{array}{c}\mathrm{EFE}_{\mathrm{qi}} \\
, \mathrm{y}_{6 \mathrm{i}}\end{array}$ & $\begin{array}{c}\mathrm{HV}_{\mathrm{i}}, \\
\mathrm{y}_{7 \mathrm{i}}\end{array}$ \\
\hline 1 & 0.215 & 0.532 & 0.138 & 0.535 & 0.535 & 0.534 & 0.538 \\
\hline 2 & 0.191 & 0.152 & 0.130 & 0.886 & 0.886 & 0.886 & 0.776 \\
\hline 3 & 0.500 & 0.533 & 0.881 & 0.141 & 0.130 & 0.124 & 0.160 \\
\hline 4 & 0.476 & 0.326 & 0.529 & 0.874 & 0.537 & 0.692 & 0.310 \\
\hline 5 & 0.821 & 0.881 & 0.204 & 0.842 & 0.850 & 0.857 & 0.505 \\
\hline
\end{tabular}

Based on the results shown in table 4 , we start the second stage of the modelling. The task is the separate evaluation of grinding quality for two sets of attributes: $\mathrm{e}=\overline{1 ; 3}$ and $\mathrm{e}=\overline{4 ; 6}$. The model includes four variables: three inputs and one output (figure 1).

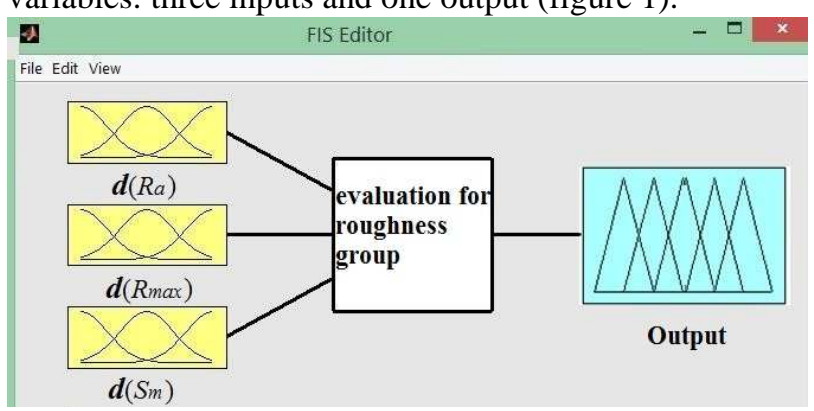

Fig. 1. Complex evaluation system of parts quality parameters for roughness group

The value for each input variable lies in the interval of $[0 ; 1]$ (table 5). And the degree of desirability including 5 estimates of VP. P. Sat. G. VG (table 6) was involved for the output variable. Microhardness was 
excluded from the analysis of input parameters due to its being represented by one attribute.

TABLE V. NUMERICAL RANGES OF INPUT VARIABLE

\begin{tabular}{|l|c|c|c|}
\hline $\begin{array}{l}\text { Type of } \\
\text { estimation }\end{array}$ & \multicolumn{3}{|c|}{ Input parameters } \\
\hline Linguistic & $\mathrm{Bad}$ & Normal & Good \\
\hline Numerical & {$[0.1 ; 0.5]$} & {$[0.1 ; 0.5 ; 0.5 ; 0.9]$} & {$[0.5 ; 0.9]$} \\
\hline
\end{tabular}

TABLE VI. NUMERICAL RANGES OF OUTPUT VARIABLE

\begin{tabular}{|l|c|c|c|c|c|}
\hline $\begin{array}{l}\text { Type of } \\
\text { estimation }\end{array}$ & \multicolumn{5}{|c|}{ Output parameters } \\
\hline Linguistic & VB & B & Sat & G & VG \\
\hline \multirow{2}{*}{ Numerical d } & {$[0.0 ;$} & {$[0.2 ;$} & {$[0.37 ;$} & {$[0.63 ;$} & {$[0.8 ;$} \\
& $0.2)$ & $0.37)$ & $0.63)$ & $0.80)$ & $1.00]$ \\
\hline Note: VB - very bad. B - bad. Sat - satisfactory. G - good. VG - \\
very good.
\end{tabular}

Table 7 shows after-the-second-stage results of modelling. It was found that the fuzzy model using allows easy access and searching for optimal HPW for the individual and combined parameters.

From table 7 it is seen that wheel 5SG (i=3) has the best cutting abilities for roughness parameters with $\mathrm{d}=0.714$; and wheel $39 \mathrm{C}(\mathrm{i}=2)$ has the worst ones with $\mathrm{d}=0.23$. In terms of form accuracy, the highest estimate was obtained during 39C (i=2) abrasive wheel grinding with $\mathrm{d}=0.897$, and the lowest for wheel 5SG (i=3) - with $\mathrm{d}=0.114$. For microhardness the optimal cutting ability was obtained for $39 \mathrm{C}(\mathrm{i}=2)$ tool grinding $(\mathrm{d}=0.776)$, and the worst - for 5 SG $(i=3)$ tool grinding $(d=0.160)$. The discrepancy of grades of the cutting ability of wheels for different quality parameters makes it difficult to select their optimal characteristics.

TABLE VII. SECOND STAGE RESULTS OF FUZZY MODELLING

\begin{tabular}{|c|c|c|c|c|c|c|}
\hline \multirow{2}{*}{$\begin{array}{c}\text { Wheels } \\
\mathrm{i}=\overline{1 ; 5}\end{array}$} & \multicolumn{2}{|c|}{ Roughness } & \multicolumn{2}{|c|}{ Form accuracy } & \multicolumn{2}{|c|}{ Microhardness } \\
\hline & $\begin{array}{l}d_{i \cdot .} e \\
=1 ; 3\end{array}$ & $\begin{array}{l}\text { Concl } \\
\text { usion }\end{array}$ & $\begin{array}{l}d_{i . . e} \\
=\overline{4 ; 6}\end{array}$ & $\begin{array}{l}\text { Concl } \\
\text { usion }\end{array}$ & $\begin{array}{l}d_{i .} e \\
=7\end{array}$ & $\begin{array}{l}\text { Concl } \\
\text { usion }\end{array}$ \\
\hline 1 & 0.160 & VB & 0.513 & Sat & 0.538 & Sat \\
\hline 2 & 0.121 & VB & 0.897 & VG & 0.776 & $\mathrm{G}$ \\
\hline 3 & 0.714 & G & 0.115 & VB & 0.160 & VB \\
\hline 4 & 0.433 & Sat & 0.718 & $\mathrm{G}$ & 0.310 & $\mathrm{~B}$ \\
\hline 5 & 0.673 & $\mathrm{G}$ & 0.868 & VG & 0.505 & Sat \\
\hline
\end{tabular}

The third (final) stage of modeling should be carried out only if it is necessary to optimize the cutting abilities of the HPW for all parameters of surface quality e = $\overline{1 ; 7}$. At this stage, the desirability function is denoted as $\mathrm{d}_{\mathrm{i} . .}$, where the additional point " $\bullet$ in the index characterizes the complete (integral) averaging of the "output". i.e. for all $\mathrm{e}=(1 ; 7)$ and partially i for a number of HPW. To do this, we created a model of four variables: three inputs and one output (figure 2). The values for each variable of the input according to the desirability function correspond to the output variables (table 8), and their linguistic values are also represented by five classes (see table 6 ).

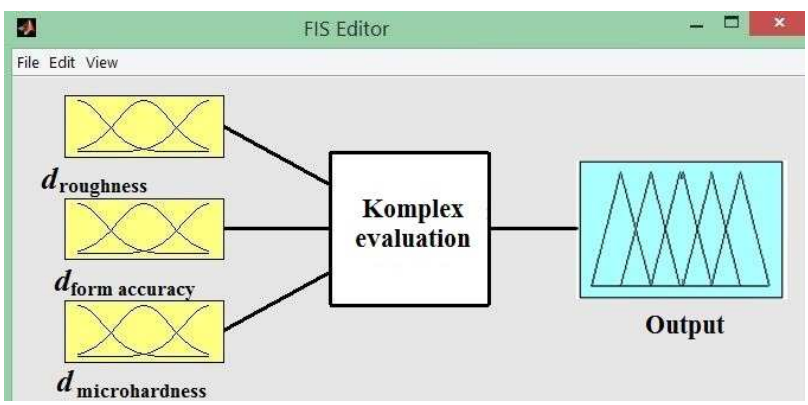

Fig.2. Complex evaluation system of parts' surface quality for all investigated parameters

It is established that during the complex evaluation of cutting abilities, the top position got the wheel $08 \mathrm{C}(\mathrm{i}=5)$ with $\mathrm{d}=0.707$, while the last position went to the circle 5SG ( $i=3$ ) with $d=$ of 0.219 . It is revealed that the best results (X-evaluation) for the surface quality of grinded parts are predicted for wheels of silicon carbide green (08C and 39C).

TABLE VIII. FINAL STAGE RESULTS OF FUZZY MODELING

\begin{tabular}{|l|c|c|}
\hline \multicolumn{1}{|c|}{ Wheels $(\mathbf{i}=\overline{\mathbf{1} ; \mathbf{5})}$} & $\mathbf{d}_{\mathbf{i} \bullet}$ & Conclusions \\
\hline 37C 46 I 12 VP (1) & 0.323 & poor \\
\hline 39C 46 I 12 VP (2) & 0.640 & good \\
\hline 5SG 46 K 12 VXP (3) & 0.219 & bad \\
\hline 63C 40 L 7 V (4) & 0.493 & satisfactory \\
\hline 08C 046 I 12 V01 P02 (5) & 0.707 & good \\
\hline
\end{tabular}

Wheel 63C40L7V (i=4) of Russian production was satisfactorily rated and took the last place in cutting abilities. Sinter-corundum HPW (i=5) was tested as an experiment and showed the worst results.

\section{CONCLUSIONS}

1. The involvement of fuzzy logic and statistical processing of observations proved to be an effective tool in the searching for optimal HPW by cutting abilities.

2. Each stage of fuzzy modeling allows one to solve variety of production tasks depending on the initial design and engineering requirements. Thus, the first stage gives an opportunity to select the characteristics of HPW as it is necessary to provide one separate quality parameter. The second stage allows evaluating HPW cutting properties for the parameter group. The third stage of modelling is to optimize the topography for the whole range of investigated parameters.

3. According to fuzzy logic modelling results in MATLAB, it was found that the best cutting ability of HPW for an integral complex of studied parameters while grinding high-strength aluminum alloy 1933 T2 was predicted for wheels 08C046I12V01P02 and 39C46I12VP with a rating of «good».

\section{References}

[1] L.A. Pankov, N.V. Kostin, Belt grinding of high-strength alloys, M.: Mechanical engineering, 1978.

[2] V.A. Shalnov, Grinding and polishing of high-strength materials, M.: Mechanical engineering, 1972.

[3] I.V. Dunhin-Barkovski, A.N. Kartashova, Measurement and analysis of surface roughness, roundness and surface waviness, M.: Mechanical engineering, 1978.

[4] M.B. Brovkova, Systems of artificial intelligence in mechanical engineering, SSTU, ISBN 5-7433-1384-9, 2004.

[5] Y.M. Ali, L.C. Zhang, "A fuzzy model for predicting burns in surface grinding of steel," International Journal of Machine Tools and Manufacture, vol. 44, pp. 563-571, 2004. 
[6] Y.M. Ali, L.C. Zhang, "Surface roughness prediction of ground components using a fuzzy logic approach," Journal of Materials Processing Technology, vol. 89-90, pp. 561-568, 1999.

[7] D.A. Viatchenin, Fuzzy methods of automatic classification, Minsk, UP Tekhnoprint publ, 2004.

[8] Ya.I. Soler, Chi Kien Nguyen, "Choice of the wheels during the pendular grinding of the aluminum alloy V95ochT2 according to macrogeometric criterion," International Journal of Applied Engineering Research. India, vol. 11, Issue 3, pp. 1787-1796, 2016.

[9] Perfection of abrasive technology, Norton catalog, 2009.

[10] M. Hollander, D.A. Wolfe, Nonparametric statistical methods, New Jersey, Wiley-Interscience, 1999.
[11] L. Sachs, Applied Statistics: A Handbook of Techniques, New York, Springer-Verlag, 1984.

[12] D. Wheeler, D. Chambers, Statistical process management trans. from English, Moscow: Alpina Business Books, 2009.

[13] E.C. Harrington, The desirability function. Industrial Quality Control, vol. 21, pp. 494-498, 1965.

[14] Ya.I. Soler, Manh Tiem Nguyen, "Selection of Highly Porous CBN Wheels in the Multiparametric Modeling of Topography for the Grinding of Stainless Steel Parts Using Fuzzy Logic," Russian Engineering Research, vol. 36, № 11, pp. 965-973. 2016. 